\title{
Post Censal Surveys in Great Britain
}

\author{
by Robert Barnes \\ Office of Population Censuses and Surveys \\ London
}

\section{Introduction}

Censuses of population have been carried out in Great Britain every ten years since 1801 with the exception of 1941. In addition a mid-term census was conducted in 1966 on a sample of $10 \%$ of the population. The next census is being planned for April 1991. Censuses in Britain are still carried out in a conventional way in that data are collected through enumeration procedures designed for the purpose rather than from registers. Specially recruited enumerators are used both for the delivery and the collection of forms.

Post censal surveys are of much more recent origin - the first having followed the 1961 Census. They have been of three kinds:

- post-enumeration surveys to evaluate the cover age and quality of the census;

- follow-up surveys which use the census as a frame from which to draw samples of groups of the population for more detailed enquiry;

- a longitudinal study which for a sample of about $1 \%$ of the population links data from successive censuses together with vital events registered during the inter-censal period.

\section{Post enumeration surveys (PES)}

The first post enumeration survey was carried out in 1961. Its aim was to assess the coverage and quality of the 1961 Census in England and Wales. Although separate from the main census, the checks were carried out by census personnel. The sample for the coverage check comprised a systematic random selection of 2,500 enumeration districts (EDs) as first stage units. Within each a 'plot' was identified containing roughly twenty addresses bounded by features that could be identified on the ground. A shortcoming of the system was that it did not provide adequate checks of coverage error arising at the boundaries of enumeration districts. The check produced an estimate of net under enumeration of $0.2 \%$ but the General Report on the 1961 Census ${ }^{2}$ said "The design of the enquiry was such that the quality of the result may be suspect but there is no information on this".

The quality check sample was selected from the same 'plots' as the coverage check. In all about 17,500 addresses were revisited for voluntary interviews within about three weeks of the census date. Census enumerators were used for this purpose but were not skilled interviewers. Again the General Report comments on the shortcomings of the study. "This fact and the very limited instruction which it was practicable to give them were contributory factors in the failure of the postenumeration survey to give satisfactory answers to some of the questions that were included".

In 1966 a quality check on the sample census was carried out by the Social Survey Division of the Central Office of Information. This was a government organisation separate from that responsible for the census itself. A sample of just over 5,200 households was selected from 300 EDs in England and Wales. There were several key features of this quality check survey which were to set the pattern for similar studies carried out in conjunction with future censuses.

- Whereas cooperation in the census was, and still is, compulsory, the post-enumeration survey was voluntary. All sample surveys of households and individuals in Britain are voluntary. Response to the 1966 Quality Check was $95 \%$.

- Whereas the census employed a large force of temporarily recruited enumerators, the survey used highly trained and experienced interviewers.

- The survey used detailed questionnaires to ascerain the 'true' answer to topics which in the census were covered by just one or two questions.

- Survey interviewers had copies of the informant's answers on the census form so that they could probe any discrepancies. This not only improves the quality of the check but also provided some reasons for the differences.

- The survey sought interviews from each adult in a household and so relied far less on proxy responses than did the census.

- In order to avoid discrepancies arising through genuine change between the time of the census and the time of the survey, it was important that the survey took place soon after the census. In fact the survey fieldwork was carried out between two and three months after the 


\section{date of the census.}

The results of the quality check were published ${ }^{3}$ and indicated that answers to a number of questions on the census form were in error to a substantial degree. The worst item was the question on the number of rooms in a household - this was misclassified in approximately one case in five.

Coverage and quality checks were again carried out on the 1971 Census. As before the coverage check was conducted in England and Wales by census officers. Although the check showed an undercount of only $0.23 \%$, the check was not considered entirely successful from a technical point of view. The General Report on

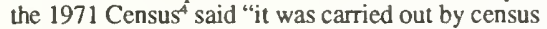
officers some of whom would still have been busy with other work on the census. Some census officers might have viewed the check as a fault finding mission and in consequence would not have been fully motivated to ensure its success".

In fact it was demonstrated that the accuracy of the coverage check was poorer than that of the census itself since there were more addresse found in the census but missed by the coverage check than vice versa. Neither did the coverage check provide a reliable measure of the extent of over counting - that was provided by other means. Taking account of the deficiencies of the check it was finally concluded that a more realistic figure for the net undercount was about twice that shown by the check.

The 1971 quality check was conducted by means of a post enumeration survey, covering the whole of Great Britain, by interviews at just under 5,000 addresses. The response rate was $85 \%$. The check was again carried out by the Social Survey which had in 1970 become a

division of the same Office which was responsible for the census - the Office of Population Census and Surveys. As with the coverage check there were unsatisfactory aspects about the quality check. It was originally planned that fieldwork should be completed within about two months of the census. In the event the work did not start till then and, because of difficulties in transferring census information from one division to the other, it proceeded slowly. Eventually fieldwork was completed about five months after census night. Because of weaknesses in the design of the check and the length of time to complete fieldwork, a number of important aims of the check were not achieved. For example there was no assessment possible of the accuracy with which questions on household tenure and amenities were answered.

In 1981 coverage and quality chocks were carried out but this time both were undertaken by the Social Survey Division of OPCS. This provided a much more integrated approach to census evaluation.

For this coverage check roughly 1,000 EDs (about $1 \%$ ) were selected in England and Wales ${ }^{5}$ and all addresses in them were thoroughly relisted by trained interviewers to see if any had been missed by the census enumerators. The EDs were selected in blocks of four, adjacent to each other so that enumeration of ED boundaries could be checked. Different samples of addresses were selected within the EDs to see whether persons had been left off census forms for addresses otherwise correctly enumerated, to see whether anyone had been missed in addresses enumerated as vacant or non-residential and to check especially the enumeration of multi-household addresses.

This was a much more rigorous approach than had been used in 1971. Moreover in 1971 no attempt had been made in the field to reconcile discrepancies. In 1981 the interviewers were given copies of census listings and so could check by means of personal interview numbers of persons missed in non-enumerated addresses. Also in 1981, unlike previous checks, discrepancies in the number of persons present in enumerated households were taken up with the informant, enabling the interviewer to form a more definite idea as to whether the census form or the post enumeration information was correct. There was one other way in which the 1981 check was superior to that of its predecessors. All EDs were graded on the basis of 1971 census data for expected difficulty of enumeration. The design used for the 1981 post enumeration survey over sampled, by a factor or two, these 'difficult' EDs, since it was hypothesized that such EDs would be likely to produce more enrors.

However in spite of the thoroughness with which the 1981 coverage check was carried out and the improvements made over previous such studies, there are inherent difficulties in checking the coverage of a census using re-enumeration methods. Because of the cost of the approach, the samples have to be fairly small and the sampling errors are therefore relatively large - especially at the sub-national level. Also in spite of the thoroughness of the methods it is likely that some of the persons and addresses missed in the census will have been missed in the survey too - for similar reasons. Therefore in 1981 , as in previous census evaluations, in addition to the post enumeration survey, checks were made also against independent administrative sources for particular groups of the population. For example checks were made for children aged $0-9$ with data on registered births and deaths and making allowances for migration, for infants aged $0-1$ with birth records, for children of school age with numbers on school rolls, and the census count of people of retirement age was compared with the records of the numbers receiving State Retirement Pensions. These checks confirmed that the level of under enumeration in the 1981 Census was small even though it may have been slightly higher than the half per cent found by the post enmeration overage check.

In addition to the post enumeration check for coverage, a sample of about 5,000 households throughout Britain within the EDs selected for the coverage check was revisited for detailed interviews to check the accuracy of answers given on census forms. Response to this post enumeration quality check survey was over $90 \%$. All fieldwork was completed within three months of the date of the census. The 1981 census form was the shortest for fifty years. Compared with many items which might have been included, and which are in other countries, the items in the British census might have been regarded as 
relatively straightforward and commonplace. Nevertheless gross error rates of $8 \%$ or more were found on five of the sixteen variables examined. For two of these the error was over $25 \%$ (and again the worst case was the question on number of rooms) and for some sub-groups the gross errors were even larger. The relative importance of these errors depends on the uses made of the information - for example the error rate reduced substantially when classifications were collapsed into fewer and simpler categories and, in any case, the net errors, in distributions, were smaller.

Improvements were made for the 1981 post enumeration survey in regard to publication of the results, compared with previous censuses. The full repor ${ }^{6}$ took a few years to produce but key results were published more quickly in the form of summary monitors both for the coverage check and the quality check?

The 1981 Census quality check also provided an opportunity to carry out a study to measure the coverage and quality of the electoral register. ${ }^{8}$ This had first been done, although in a more limited way, in conjunction with the 1966 quality check. The 1981 study covered the whole of Great Britain and measured the extent of both persons who were eligible to be on the electoral register but who were not, and those who were on the register but for whom there was no census form or for whom census details suggested they were not eligible.

The results showed that just under 7 per cent of those who should have been on the register were not and that the same proportion of names on the register should not have been. The under representation was especially high in Inner London (14 per cent), and among those aged 17 (24 per cent), and those who had recently moved (27 per cent). These figures represented a deterioration since the register had previously been checked in 1966. It is planned to carry out a similar check in 1991.

\section{Follow-up surveys}

The first survey to use the census as a sample frame for more detailed enquiry was a follow-up to the 1966 sample census. This was a study on diet and health concentrating especially on sugar intake because of the supposed relationship between that and myocardial infarction. This was a postal enquiry of some 20,000 persons conducted in 1967/68. 1966 sample census returns were used as a sample frame because the sample required was of men between ages 45 and 65 in the London area. Moreover the subsequent fate of the sample members could be traced through death registers also maintained by the same Office. Considering the length of time between the census and the survey, the percentage of returns was high at $85 \%$. Of these $89 \%$ had completed the forms ( $75 \%$ response overall). Of the remainder the majority were returned as gone away, deceased etc. Important aspects of this survey were that data were collected by the same organisation that carried out the census and that procedures to ensure the anonymity of sample members were strictly adhered to before the data records were released to outside researchers for analysis.
The tracing of sample members through death registers has continued ever since and, although no results have yet been published on the relationship between sugar and heart disease the study has yielded other results relating diet and disease - in particular between tea and coffee consumption and cancer. ${ }^{9}$

Following the 1971 Census there were three such enquiries. The first was the Income Follow-up Survey. ${ }^{10}$ There had been pressure to include an income question in the census itself but tests carried out in 1968 and 1969 indicated the severe problems of dealing with such a complex topic with simple questions suitable for a census form. It was also found that the inclusion of income as a possible topic in a compulsory census aroused hostility among some sections of the British public. Therefore it was decided that the Census division of OPCS should carry out a voluntary survey, by post, on $1 \%$ of the population throughout Great Britain in such a way that the answers could be linked with the census forms of the sampled individuals. Although it was intended to carry out the study as quickly as possible after the census, the adverse publicity which the 1971 Census attracted caused the follow-up study to be postponed and it was eventually conducted over a year later. Because of this and because of the subject of the enquiry, the response was only $40 \%$ and a substantial volume of imputation, using hot deck methods, was carried out. The study was not repeated after the 1981 Census.

A second follow-up survey to the 1971 Census was on the subject of qualified manpower. This also was a voluntary, postal enquiry carried out by Census division. The object was to follow up a sample of those who on the census form had reported that they had academic, professional or vocational qualifications, to seek more information about the qualifications, their jobs and their employment income. However because of competing demands of other work, there were delays in completing this survey. In the end the need for the results was overtaken by other events and the report was not published.

The third follow-up to the 1971 Census was the so-called Nursing Survey. ${ }^{11}$ This was particularly important not only because of the topic of enquiry but because the criticism which the survey attracted had important consequences for follow-up enquiries of future censuses. The purpose of the study was to obtain information from persons with nursing or midwifery qualifications, who were of working age but who were not practising nursing or midwifery. The census provided an ideal frame from which to select a sample of such persons who would otherwise would have been especially difficult to locate. A sample just over 700 throughout Great Britain was selected for voluntary face-to-face interview and of these $89 \%$ agreed to cooperate. The fieldwork was carried out within four to five months of the census date.

The study was carried out by the Social Survey Division of the then recently formed OPCS. Census Division, of the same Office, selected the sample and passed the names and addresses to the Social Survey. Because both 
divisions were part of the same Office there was no breach of the confidentiality undertakings given at the time of the Census. But this fact was not always appreciated by the public, nor by some sections of the press or even the research communities and there was considerable criticism of the practice of using census forms for this kind of purpose. Even an investigatory team from the Royal Statistical Society commented in 1973 that "This use was, in our opinion, only doubifully covered by the wording printed on the census form and by other public pronouncements on the confidentiality of information given in the census operation". Nor did the reference to the nursing survey was still being made at the time of, and after, the 1981 Census even though there were no follow-up enquiries of this kind attached to that Census.

As a result of the controversy, procedures changed after 1971. Although there were no such studies following the 1981 Census, had there been they would have had to have been announced to Parliament before the census was carried out. Similarly for 1991, the White Paper published in July $1988^{12}$ announcing the government's intentions to take a census 1991, contained the following paragraph.

"The census may be used as a source from which to select samples for further more detailed surveys, for example of people with particular educational qualifications. Response to any such survey would be voluntary.... Information would be treated in the same strict confidence as information given on the main census forms. It is too early to know whether there will be a need for any such census-linked surveys and the topics that might be covered, but Parliament will be informed before the census is taken about the subject matter of any census-linked survey which it was proposed to conduct following the census and all those completing the census forms would also be informed of the possibility of being asked to participate in such a voluntary survey after the Census."

The White Paper also emphasized that any such censuslinked surveys would have to be handled by OPCS (and by the General Register Office in Scotland). This means that the work cannot be contracted to commercial or academic research agencies.

\section{The longitudinal study ${ }^{13}$}

This is a rather special form of post-census survey. It is a data linkage exercise and involves no specific enquiry of the sample members. The study comprises a sample of persons in England and Wales with birthdays falling on each of four specific days in the year and therefore provides roughly a $1 \%$ sample of the population. The study started with the 1971 Census records for the sample members. Between 1971 and 1981 mortality and migration data were added to the records from registration data also held by OPCS. Also added to the records were live and still births to sample members, deaths of children under one year of age to sample members, death of a spouse and cancer registration. In addition children bom on any of the four sample days during any year between the censuses were added to the sample, thus maintaining it at approximately 1\%. In 1981 the new intercensal data on migration and vital events has continued to be added since then. Proposals are now being drawn up for further links to be made to the 1991 Census.

Initially the longitudinal survey included about 530,000 people selected from the 1971 Census. By the time of the 1981 Census some 121,000 more had been added to the sample because of new births, immigration, or because they were found for the first time in 1981. And 115,000 were removed from the sample because of death, emigration or because they could not be traced in the 1981 Census. Therefore the sample after the 1981 Census records are available, numbers in particular subgroups are as follows:

$\begin{array}{lc}\text { Characteristics in 1971 } & \frac{\text { Number for whom 1981 }}{\text { details linked }} \\ \text { Children under 16 } & 120,000 \\ \text { Teenagers 13-19 } & 40,000 \\ \text { Divorced } & 5,000\end{array}$

Lone parents with dependent $\quad 5,000$

dependent children

Men aged 50-64

40,000

Persons aged 75 or over

10,000

Unemployed

10,000

Migrants

130,000

There are many important uses for this longitudinal data set for such a large sample of the population. They are too numerous to list here but they include the relationship between socio-economic circumstances and mortality in relation to housing and household circumstances, sociodemographic differentials in cancer incidents and survival, the relationships between socio-demographic factors and migration (i.e. the propensity to change address about the time of events such as marriage, birth of children, birth or bereavement), fertility pattems of young women according to family background characteristics, and social and occupational mobility. Apart from this kind of general analysis, the data set is also large enough to focus on particular sub-groups or geographical areas.

\section{Conclusions}

Post censal surveys have been carried out in Great Britain for nearly 30 years. They have been used to evaluate the census, ${ }^{14}$ to take advantage of the census as a sampling frame and to provide longitudinal data for particular topics. They have not all been successful and problems both technical and ethical have arisen. However post censal surveys will almost certainly be a feature 
of future censuses in Britain and lessons learned from previous experiences should help to ensure that past difficulties are avoided. The main lessons are that field work for follow-up studies should be completed as soon as possible after the census, that the field workers should be trained interviewers skilled in administering complex questionnaires, that the public and Parliament should be informed in advance of the intention to use census data for this kind of purpose, and that census evaluation studies should be carried out by staff who were not directly involved with the census operation itself.

${ }^{1}$ Presented at the IFDO/IASSIST 89 Conference held in Jerusalem, Israel, May 15-18, 1989.

${ }^{2}$ General Report on the 1961 Census.

${ }^{3}$ Gray \& Gee. A Quality Check on the 1966 Ten Per Cent Sample Census of England and Wales. HMSO, 1972.

¿Census 1971. General Report Part 3, Statistical Assessment. OPCS, 1983.

${ }^{5}$ Separate coverage checks were carried out in Scotland.

${ }^{6}$ Britton \& Birch. 1981 Census Post Enumeration

Survey. HMSO, 1985.

'Evaluation of the 1981 Census. OPCS Monitor CEN 82/3, 1982.

Evaluation of the 1981 Census: Post Enumeration Survey. OPCS Monitor CEN 83/4, 1983.

Evaluation of the 1981 Census: Post Enumeration Survey (Quality Check). OPCS Monitor CEN 84/3, 1984.

${ }^{8}$ Todd \& Butcher. Electoral Registration in 1981. OPCS, 1982

${ }^{9}$ Leo Kinlev et al. Coffee and pancreas cancer; controversy is part explained. The Lancet, Feb 1984.

L.J. Kinlev et al. Tea consumption and cancer. British Journal of Cancer, no. 58. Macmillan, 1988.

${ }^{10} 1971$ Census Income Follow-up Survey. OPCS Studies on Medical and Population Subjects, no. 38. HMSO, 1978.

"Sadler \& Whitworth, Reserves of Nurses. HMSO, 1975.

${ }^{12} 1991$ Census of Population. Cm 430. HMSO, 1988.

${ }^{13}$ The Longitudinal Study 1971-1981. Cen 81Ls. HMSO, 1988.

Brown \& Fox, OPCS longitudinal study: ten years on. Population Trends, no. 37. HMSO, Autumn 1984.

${ }^{14}$ Whitehead. The GRO use of social surveys. Population Trends, no. 48. HMSO, Summer 1987. 